\title{
Genistein induces oestrogen receptor- $\alpha$ gene expression in osteoblasts through the activation of mitogen-activated protein kinases/NF-кB/ activator protein-1 and promotes cell mineralisation
}

\author{
Mei-Hsiu Liao ${ }^{1}$, Yu-Ting Tai ${ }^{2}$, Yih-Giun Cherng ${ }^{3}$, Shing-Hwa Liu ${ }^{4}$, Ya-An Chang ${ }^{2}$, \\ Pei-I Lin ${ }^{1}$ and Ruei-Ming Chen ${ }^{1,2,5 *}$ \\ ${ }^{1}$ College of Medicine, Graduate Institute of Medical Sciences, Taipei Medical University, 250 Wu-Xing Street, \\ Taipei 110, Taiwan \\ ${ }^{2}$ Cell Physiology and Molecular Image Research Center, Taipei Medical University-Wan Fang Hospital, Taipei, Taiwan \\ ${ }^{3}$ Department of Anesthesiology, Shuang-Ho Hospital, Taipei Medical University, Taipei, Taiwan \\ ${ }^{4}$ College of Medicine, Institute of Toxicology, National Taiwan University, Taipei, Taiwan \\ ${ }^{5}$ Anesthetics and Toxicology Research Center, Taipei Medical University Hospital, Taipei, Taiwan \\ (Submitted 28 March 2013 - Final revision received 13 May 2013 - Accepted 30 May 2013 - First published online 5 July 2013)
}

\section{Abstract}

Oestrogen and oestrogen receptors (ER) play critical roles in the maintenance of bone remodelling. Genistein, structurally similar to $17 \beta$-oestradiol, is a phyto-oestrogen that may be beneficial for treating osteoporosis. In the present study, we evaluated the effects of genistein on the regulation of $E R \alpha$ gene expression and osteoblast mineralisation using MC3T3-E1 cells and primary rat calvarial osteoblasts as our experimental models. Exposure of MC3T3-E1 cells and primary rat osteoblasts to genistein at $\leq 10 \mu \mathrm{M}$ for $24 \mathrm{~h}$ did not affect the cell morphology or viability. However, treatment of MC3T3-E1 cells with $10 \mu \mathrm{M}$-genistein enhanced the phosphorylation of extracellular signal-regulated kinase 1/2, p38 mitogen-activated protein kinase (MAPK) and c-Jun N-terminal kinase 1/2 in a time-dependent manner. Sequentially, genistein increased the translocation of NF-кB and c-Jun from the cytoplasm to the nucleus. Consequently, exposure of MC3T3-E1 cells to genistein induced $E R \alpha$ mRNA expression in concentration- and time-dependent manners. In parallel, the amounts of cytosolic and nuclear ER $\alpha$ in MC3T3-E1 cells were increased following genistein administration. Additionally, genistein also increased the levels of $E R \alpha$ mRNA and nuclear ER $\alpha$ protein in rat calvarial osteoblasts. A bioinformatic search revealed that there are several ER $\alpha$-specific DNA-binding elements in the $5^{\prime}$-promoter regions of the bone morphogenetic protein-6, collagen type I and osteocalcin genes. As a result, genistein could induce the expressions of these osteoblast differentiation-related genes in primary rat osteoblasts. Co-treatment with genistein and traditional differentiation reagents synergistically increased osteoblast mineralisation. Therefore, the present study showed that genistein can induce $E R \alpha$ gene expression via the activation of MAPK/NF- $\mathrm{B} /$ activator protein-1 and accordingly stimulates differentiation-related gene expressions and osteoblast mineralisation.

\section{Key words: Genistein: Osteoblasts: Oestrogen receptor- $\alpha$ : Mitogen-activated protein kinase mechanisms: Osteoblast} mineralisation

Bone structure is maintained by a dynamic balance between osteoblast-mediated bone formation and osteoclastmediated bone resorption ${ }^{(1,2)}$. In particular, osteoblasts, differentiated from mesenchymal stem cells, play critical roles in bone formation ${ }^{(3)}$. During osteogenesis, stem and primitive osteoprogenitors that are differentiated from stromal stem cells can replace osteoblasts, which promote bone turnover and fracture healing ${ }^{(4)}$. Additionally, sequential differentiation of these precursor cells leads to osteoblast maturation and mineralisation ${ }^{(3,4)}$. A complicated network of various proteins is involved in the regulation of osteogenesis $^{(5,6)}$. For example, endogenous bone morphogenetic proteins (BMP) are multifunctional growth factors that participate in matrix differentiation and bone formation ${ }^{(7,8)}$. Osteocalcin (OCN) can act as an early osteoblast marker that controls osteoblast function and bone extracellular matrix mineralisation $^{(9)}$. In addition, collagen type I (Col I), an extracellular matrix protein, stimulates osteoblast adhesion

\footnotetext{
Abbreviations: AP-1, activator protein-1; BMP, bone morphogenetic protein; Col I, collagen type I; DR, differentiation reagent; ER, oestrogen receptor; ERK, extracellular signal-regulated kinase; JNK, c-Jun N-terminal kinase; MAPK, mitogen-activated protein kinase; MTT, 3-(4,5-dimethylthiazol-2-yl)-2, 5-diphenyltetrazolium bromide; OCN, osteocalcin.
} 
and differentiation ${ }^{(10,11)}$. The expressions of all these differentiation-related genes can be regulated by several local and systemic factors, including oestrogen, growth factors and cytokines $^{(6,12,13)}$.

Oestrogen acts as the main regulator of skeletal growth and maintenance by adjusting osteoblast differentiation and metabolism $^{(12)}$. The levels of serum oestrogen are significantly diminished with ageing and concurrently bring about an imbalance of osteoblastogenesis and osteoclastogenesis ${ }^{(12,14)}$. As a result, reduced serum oestrogen concentrations may cause systemic diseases such as osteoporosis, leading to increased risks of bone fracture ${ }^{(15,16)}$. In the clinic, oestrogen replacement therapy has been applied to treat osteoporosis, but many side effects, including a certain cancer incidence, have been reported ${ }^{(17)}$. As an alternative, phyto-oestrogens are plant-derived compounds that exhibit effects similar to those of mammalian estrogens; they have been widely studied to explore their potential to treat osteoporosis ${ }^{(18)}$. Genistein is a non-steroidal phyto-oestrogen found in a number of plants, including lupin, fava beans and soyabeans ${ }^{(19)}$. Because of a structural similarity to $17 \beta$-oestradiol, genistein has been proposed as a potential therapeutic agent for preventing postmenopausal bone loss ${ }^{(20)}$. The major mechanism of genistein's action is the control of osteoblast metabolism through oestrogen receptor (ER)-dependent pathways ${ }^{(21)}$.

ER are a family of intracellular receptors, including ER $\alpha$ and $\mathrm{ER} \beta^{(22)}$. ER $\alpha$ has been reported to be the major regulator mediating the effects of oestrogen on bone metabolism ${ }^{(23)}$. According to the classical mechanism, oestrogen binds to ER $\alpha$ to form a receptor dimer, and then this dimer is translocated from the cytoplasm to the nucleus where it associates with co-regulatory proteins $^{(24)}$. After binding to its specific oestrogen-response elements, this ER-oestrogen complex can initiate certain gene expressions and control osteoblast differentiation ${ }^{(25)}$. Genistein may have a noteworthy impact on the prevention and therapy of postmenopausal bone loss ${ }^{(20)}$. One of the mechanisms of genistein's action is the stimulation of osteoblast maturation via an ER-dependent induction of cell proliferation-related gene expressions $^{(26)}$. Other mechanisms may be the promotion of osteogenesis and repression of adipogenic differentiation of human primary bone marrow stromal cells ${ }^{(27)}$. In addition, genistein can induce $E R \alpha$ mRNA expression in bone marrow cells $^{(28)}$. ER $\alpha$ plays an important role in the mediation of genistein-involved regulation of osteoblast differentiation and mineralisation. However, the effects of genistein on the regulation of $E R \alpha$ gene expression in osteoblasts are still not very clear. Therefore, the present study attempted to evaluate the mechanisms of genistein-induced $E R \alpha$ gene expression and the effects of genistein on the regulation of osteoblast differentiation and mineralisation using MC3T3-E1 cells and primary rat calvarial osteoblasts as the experimental models.

\section{Materials and methods}

\section{Cell culture and drug treatment}

Mouse MC3T3-E1 cells were purchased from American Type Culture Collection. Primary rat osteoblasts were prepared from neonatal rat calvaria following a sequential enzymatic digestion method described previously ${ }^{(6)}$. All procedures were performed according to the National Institutes of Health Guidelines for the Use of Laboratory Animals and approved by the Institutional Animal Care and Use Committee of Taipei Medical University (Taipei, Taiwan). Briefly, after anaesthesia, the neonatal rats were killed, and the calvarias were collected, washed and cut into pieces. The calvarial pieces were incubated in a digestion solution ( $0 \cdot 25 \%$ trypsin, $2 \mathrm{~g} / 1$ collagenases and $0 \cdot 1 \%$ EDTA) at $37^{\circ} \mathrm{C}$. After centrifugation, the primary osteoblasts were washed and cultured. MC3T3-E1 cells and primary rat osteoblasts were seeded in Dulbecco's modified Eagle's medium (Gibco-BRL) supplemented with 10\% fetal bovine serum, L-glutamine, penicillin $(65 \mathrm{mg} / \mathrm{l})$ and streptomycin $(100 \mu \mathrm{g} / \mathrm{ml})$ in $75 \mathrm{~cm}^{2}$ flasks at $37^{\circ} \mathrm{C}$ in a humidified atmosphere of $5 \% \mathrm{CO}_{2}$. Genistein purchased from sigma was freshly dissolved in dimethyl sulphoxide. These two types of bone cells were exposed to various concentrations of genistein for different time intervals. Control cells were exposed to only dimethyl sulphoxide.

\section{Assay of cell viability}

The cytotoxicity of genistein towards osteoblasts was evaluated by analyses of cell viability and morphologies ${ }^{(13)}$. Cell viability was determined by a colorimetric 3-(4,5-dimethylthiazol-2-yl)-2,5-diphenyltetrazolium bromide (MTT) assay. Briefly, $10^{4}$ cells were seeded in ninety-six-well tissue culture plates overnight. After genistein treatment, the osteoblasts were cultured with a new medium containing $0.5 \mathrm{mg} / \mathrm{ml}$ of MTT for a further $3 \mathrm{~h}$. Blue formazan products in the osteoblasts were dissolved in dimethyl sulphoxide and spectrophotometrically measured at a wavelength of $550 \mathrm{~nm}$. Cell morphologies were observed and photographed using an inverted phase-contrast microscope (Nikon).

\section{Immunodetection of phosphorylated extracellular signal-regulated kinase $1 / 2, p 38$ and c-Jun $N$-terminal kinase and $\beta$-actin proteins}

After genistein treatment, cell lysates were prepared in an icecold radioimmunoprecipitation assay buffer $(25 \mathrm{~mm}$-Tris- $\mathrm{HCl}$ ( $\mathrm{pH} 7 \cdot 2$ ) , $0 \cdot 1 \%$ SDS, $1 \%$ Triton X-100, $1 \%$ sodium deoxycholate, $0 \cdot 15 \mathrm{M}-\mathrm{NaCl}$ and $1 \mathrm{~mm}-\mathrm{EDTA})$ as described previously ${ }^{(29)}$. Protein concentrations were quantified using a bicinchoninic acid protein assay kit (Pierce). Proteins (100 $\mu$ g per well) were subjected to SDS-PAGE and transferred onto nitrocellulose membranes. After blocking, phosphorylated extracellular signal-regulated kinase (ERK) 1/2, p38 and c-Jun N-terminal kinase (JNK; Cell Signaling Technology) were immunodetected. $\beta$-Actin was detected using a mouse monoclonal antibody (Sigma) as the internal control. The bands of these proteins were quantified using a digital imaging system (UVtec).

\section{Extraction of nuclear proteins and immunodetection}

Nuclear components were extracted, and immunodetection was carried out following the method of Wu et al. ${ }^{(30)}$. After 
genistein treatment, the nuclear extracts of osteoblasts were prepared. Protein concentrations were quantified using a bicinchoninic acid protein assay kit (Pierce). Nuclear proteins $(50 \mu \mathrm{g} /$ well) were subjected to SDS-PAGE and transferred onto nitrocellulose membranes. After blocking, nuclear $\mathrm{ER} \alpha, \mathrm{NF}-\kappa \mathrm{B}, \mathrm{c-Jun}$ and c-Fos were immunodetected using specific antibodies (Santa Cruz Biotechnology). Proliferating cell nuclear antigen was immunodetected (Santa Cruz Biotechnology) as the internal standard. The intensities of the immunoreactive bands were determined using a digital imaging system (UVtec).

\section{RT-PCR and real-time PCR assays}

For the RT-PCR analyses of ER $\alpha$, Col I, BMP-6, OCN and $\beta$-actin mRNA, mRNA from MC3T3-E1 cells and primary rat osteoblasts were prepared according to a previously described method ${ }^{(31)}$. Oligonucleotide primers were designed and synthesised by Clontech Laboratories. The oligonucleotide sequences of the respective upstream and downstream primers for analyses of these mRNA were as follows: $5^{\prime}$-TCCTTCTAGACCCTTCAGTGAAGCC- $3^{\prime}$ and 5'-ACATGTCAAAGATCTCCACCATGCC- $3^{\prime}$ for $E R \alpha ; 5^{\prime}$-AAAGCCAAGAGAAACGGTGGGCAT- $3^{\prime}$ and $5^{\prime}$-GCCAATCATGTGCACCAGTTCCTT- $3^{\prime}$ for $E R \beta ; 5^{\prime}$-CTTGTCCTCATGGCTGTGAAAC- $3^{\prime}$ and $5^{\prime}$-TATTGCTGGTGCTCCTGGCTTC- $3^{\prime}$ for Col $I$; 5'-AGGATGGGGTGTCAGAGGGAGA- $3^{\prime}$ and $5^{\prime}$-GTTGTGCTGCGGTGTCACCA- $3^{\prime}$ for BMP-6; 5'-ATGAGGACCCTCTCTCTGCTC- $3^{\prime}$ and $5^{\prime}$-GTGGTGCCATAATGCGCTTG- $3^{\prime}$ for OCN and 5'-GTGGGCCGCTCTAGGCACCAA- $3^{\prime}$ and 5'-CTCTTTGATGTCACGCACGATTTC- $3^{\prime}$ for rat $\beta$-actin. The PCR products were loaded onto a $1 \cdot 8 \%$ agarose gel containing $0 \cdot 1 \mu \mathrm{g} / \mathrm{ml}$ ethidium bromide and electrophoretically separated. DNA bands were visualised and photographed under UV-light exposure. The intensities of the DNA bands in the agarose gel were quantified with the aid of a digital imaging system (Uvtec). Real-time PCR analyses were carried out using the iQSYBR Green Supermix (Bio-Rad) and the MyiQ Single-Color Real-Time PCR Detection System (Bio-Rad).

\section{Assays of osteoblast mineralisation}

Osteoblast maturation was determined by evaluating cell mineralisation using the Alizarin red $\mathrm{S}$ dye-staining proto$\mathrm{Col}^{(32)}$. Primary rat osteoblasts were treated with genistein, a differentiation reagent (DR; $10 \mathrm{~nm}$-dexamethasone, $100 \mu \mathrm{g} / \mathrm{ml}$ ascorbic acid and $10 \mathrm{~mm}-\beta$-glycerophosphate) and a combination of genistein and the DR for $21 \mathrm{~d}$. After genistein treatment, rat osteoblasts were washed with ice-cold

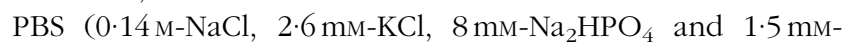
$\mathrm{KH}_{2} \mathrm{PO}_{4}$ ) and then fixed in ice-cold $10 \%$ formalin for $20 \mathrm{~min}$. The fixed osteoblasts were thoroughly rinsed and then incubated in 1\% alcian blue ( $\mathrm{pH} \mathrm{2.5}$; Fisher Scientific) for $12 \mathrm{~h}$. The sections were then incubated in Alizarin red $\mathrm{S}$ (Fisher Scientific) for $8 \mathrm{~min}$, briefly dehydrated in xylene and covered with a coverslip in Permount (Fisher Scientific). Mineralised nodules were visualised and counted under an inverted microscope. Each experiment was performed in duplicate wells and repeated three times.

\section{Statistical analysis}

Statistical differences between the control and drug-treated groups were considered significant when the $P$ value of Duncan's multiple-range test was $<0.05$. Statistical analysis between the drug-treated groups was carried out using a two-way ANOVA.

\section{Results}

The cytotoxicity of genistein towards MC3T3-E1 cells was determined (Fig. 1). Exposure of MC3T3-E1 cells to $0 \cdot 01,0 \cdot 1$, 1,10 and $100 \mu \mathrm{m}$-genistein for $24 \mathrm{~h}$ did not influence cell viability (Fig. 1(a)). Additionally, after treatment of MC3T3-E1 cells with 1,5 and $10 \mu \mathrm{m}$-genistein for $24 \mathrm{~h}$, the cell morphologies did not change (Fig. 1(b)). Exposure of MC3T3-E1 cells to $10 \mu \mathrm{m}$-genistein for $0 \cdot 5,1,3,6$ and $24 \mathrm{~h}$ did not affect the cell morphologies (Fig. 1(c)). After exposure to $0 \cdot 01,0 \cdot 1,1,10$ and $100 \mu \mathrm{m}$-genistein for $24 \mathrm{~h}$, the viability of primary rat calvarial osteoblasts was not influenced (data not shown).

The effects of genistein on the phosphorylation of mitogenactivated protein kinase (MAPK) and the translocation of NF-кB and activator protein-1 (AP-1) were immunodetected (Fig. 2). In the untreated MC3T3-E1 cells, low levels of phosphorylated ERK1/2, p38 MAPK and JNK1/2 were detected (Fig. 2(a), top three panels, lane 1). After exposure to $10 \mu \mathrm{M}$-genistein for $0 \cdot 5,1,3$ and $6 \mathrm{~h}$, the levels of phosphorylated ERK1/2 were increased in a time-dependent manner (Fig. 2(a), top panel, lanes 2-5). The phosphorylation of p38 MAPK in MC3T3-E1 cells was also time dependently enhanced following exposure to $10 \mu \mathrm{M}$-genistein for $0 \cdot 5,1,3$ and $6 \mathrm{~h}$ (lanes 2-5). When MC3T3-E1 cells were treated with $10 \mu \mathrm{m}$-genistein for $6 \mathrm{~h}$, the amounts of phosphorylated JNK1/2 increased (lane 5). $\beta$-Actin was immunodetected as the internal control (Fig. 2(a)). Exposure of MC3T3-E1 cells to $10 \mu \mathrm{m}$-genistein for $0.5 \mathrm{~h}$ increased the levels of nuclear NF-кB (Fig. 2(b), top panel, lane 2). After exposure for 1 and $3 \mathrm{~h}$, genistein enhanced the increases in the amounts of nuclear NF-кB (lanes 3 and 4). The levels of c-Jun and c-Fos in the nuclei were immunodetected (Fig. 2(b)). Treatment of MC3T3-E1 cells with genistein for 0.5, 1 and $3 \mathrm{~h}$ led to significant increases in the levels of nuclear c-Jun and c-Fos (lanes 2 and 3). Nuclear proliferating cell nuclear antigen was analysed as the internal control (Fig. 2(b)).

Analyses of RNA were performed to determine the effects of genistein on $E R \alpha$ and $E R \beta$ mRNA expressions (Fig. 3). Exposure of MC3T3-E1 cells to $1 \mu \mathrm{M}$-genistein for $6 \mathrm{~h}$ did not affect ER $\alpha$ mRNA expression (Fig. 3(a), top panel, lane 2). When the concentration reached $5 \mu \mathrm{M}$, genistein slightly induced $E R \alpha$ mRNA synthesis (lane 3). In contrast, $10 \mu \mathrm{M}$-genistein induced a strong $E R \alpha$ mRNA expression (lane 4). Treatment of MC3T3-E1 cells with $10 \mu \mathrm{m}$-genistein for 1 and $3 \mathrm{~h}$ did not influence $E R \alpha$ mRNA expression (Fig. 3(b), top panel, lanes 2 and 3). However, exposure for 6 and $24 \mathrm{~h}$ significantly induced $E R \alpha$ mRNA expression (lanes 4 and 5). The amounts of $\beta$-actin mRNA were analysed as internal controls (Fig. 3(a) and (b)). Real-time PCR analyses showed that genistein 


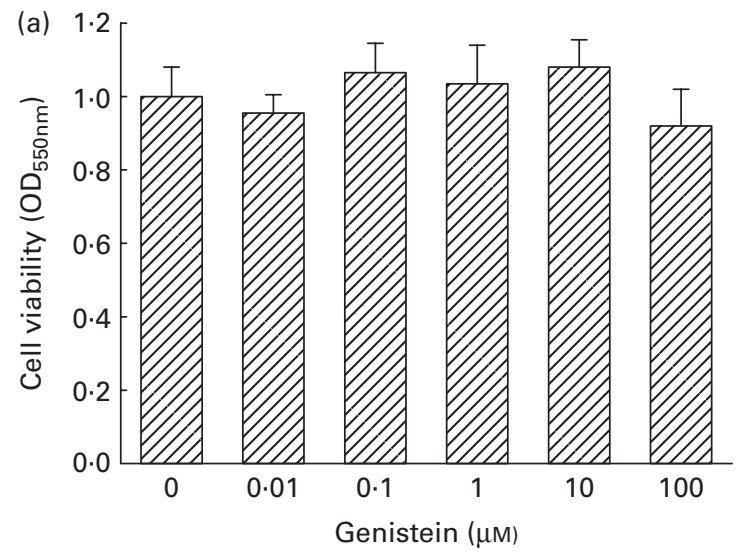

(b)

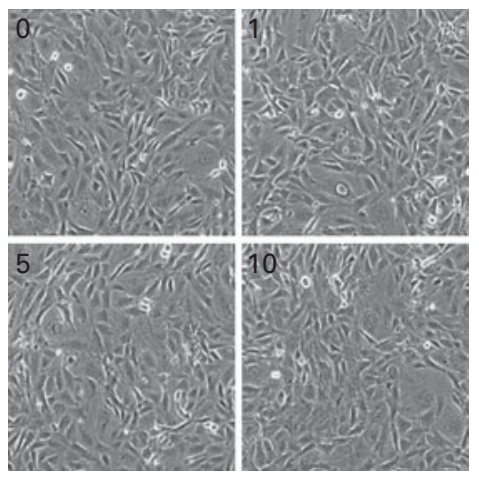

(c)
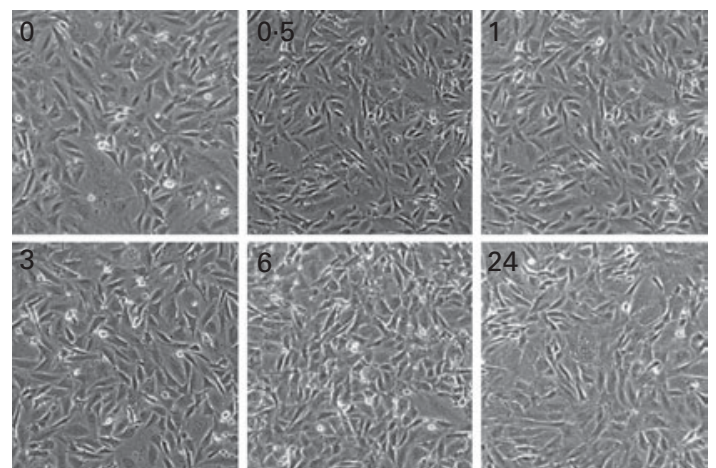

Fig. 1. Cytotoxicity of genistein towards MC3T3-E1 cells. (a) MC3T3-E1 cells were exposed to $0.01,0.1,1,10$ and $100 \mu \mathrm{M}$-genistein for $24 \mathrm{~h}$, and cell viability was determined using a colorimetric method. The morphologies of MC3T3-E1 cells were observed after exposure to (b) 1, 5 and $10 \mu \mathrm{M}$-genistein for $24 \mathrm{~h}$ or to (c) $10 \mu \mathrm{m}$-genistein for $0.5,1,3,6$ and $24 \mathrm{~h}$. Values are means $(n 6)$, with their standard errors represented by vertical bars. $\mathrm{OD}_{550 \mathrm{~nm}}$, optical density at $550 \mathrm{~nm}$.

significantly induced $E R \alpha$ and $E R \beta$ mRNA expressions by 230 and $190 \%$, respectively (Fig. 3(c)).

Immunoblotting analyses were performed to determine the effects of genistein on $\mathrm{ER} \alpha$ protein synthesis (Fig. 4). Exposure of MC3T3-E1 cells to $1 \mu \mathrm{M}$-genistein for $24 \mathrm{~h}$ did not affect the levels of ER $\alpha$ (Fig. 4(a), top panel, lane 2). In contrast, when the concentrations reached 5 and $10 \mu \mathrm{M}$, genistein increased $\mathrm{ER} \alpha$ synthesis (lanes 3 and 4). Exposure of MC3T3-E1 cells to $10 \mu \mathrm{m}$-genistein for $0 \cdot 5,1,3,6$ and $24 \mathrm{~h}$ time dependently enhanced the levels of $\mathrm{ER} \alpha$ (Fig. 4(b)). The amounts of $\beta$-actin were immunodetected as internal controls (Fig. 4(a) and (b)).

Nuclear proteins were isolated and analysed to determine the effects of genistein on the translocation of ER $\alpha$ from the cytoplasm to the nucleus (Fig. 5). Exposure of MC3T3-E1 cells to $1 \mu \mathrm{M}$-genistein for $24 \mathrm{~h}$ increased the levels of nuclear $\mathrm{ER} \alpha$ (Fig. 5(a), top panel, lane 2). After treatment with 5 and $10 \mu \mathrm{m}$-genistein, the amounts of ER $\alpha$ in the nuclei were significantly increased (lanes 3 and 4). Exposure of MC3T3-E1 cells to $10 \mu \mathrm{m}$-genistein for $0 \cdot 5,1,3,6$, and $24 \mathrm{~h}$ enhanced the nuclear ER $\alpha$ levels in a time-dependent manner (Fig. 5(b), top panel, lanes 2-6). The amounts of $\beta$-actin were immunodetected as internal controls (Fig. 5(a) and (b)).

Rat calvarial osteoblasts were prepared to evaluate the effects of genistein on the expressions of ER $\alpha$ and cell differentiation-related genes (Fig. 6). Exposure of rat osteoblasts to $10 \mu \mathrm{m}$-genistein for $6 \mathrm{~h}$ induced $E R \alpha$ mRNA expression (Fig. 6(a), top panel, lane 2). The levels of nuclear ER $\alpha$ in rat osteoblasts were significantly increased following

(a)
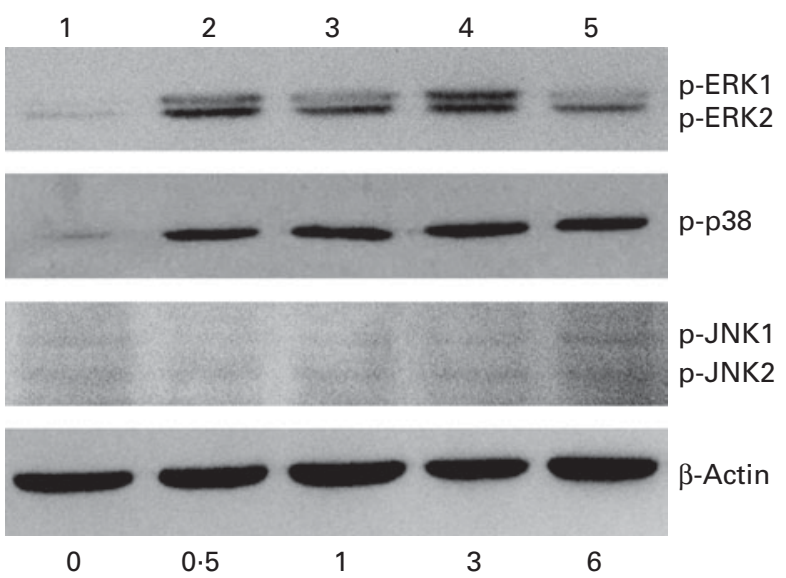

(b)
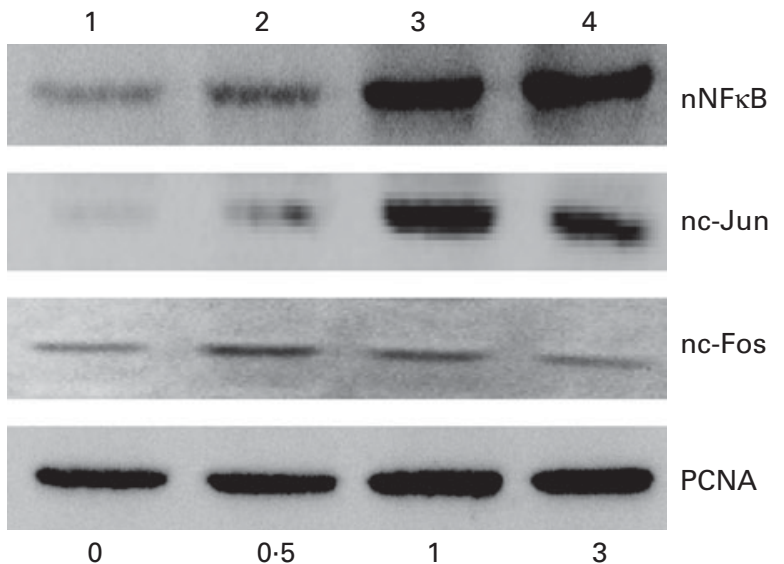

Fig. 2. Effects of genistein on the phosphorylation $(p)$ of extracellular signalregulated kinase (ERK) 1/2, p38 mitogen-activated protein kinase (MAPK) and c-Jun N-terminal kinase (JNK) 1/2 and the translocation of NF-кB, c-Jun and C-Fos. MC3T3-E1 cells were exposed to $10 \mu \mathrm{M}$-genistein for $0.5,1,3$ and $6 \mathrm{~h}$. (a) p-ERK1/2, p-p38 MAPK and p-JNK1/2 were immunodetected. The amounts of $\beta$-actin were analysed as internal controls. (b) The levels of nuclear (n) NF-кB, nc-Jun and nc-Fos were determined. The amounts of nuclear proliferating cell nuclear antigen (PCNA) were analysed as internal controls (bottom). 
(a)

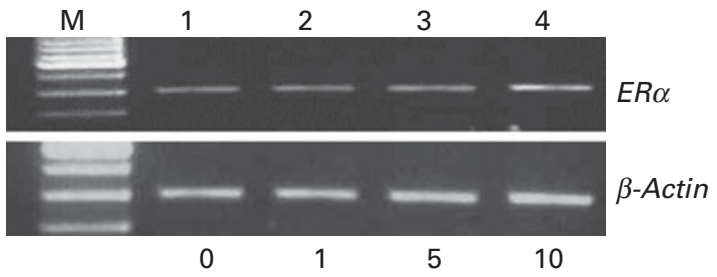

(b)

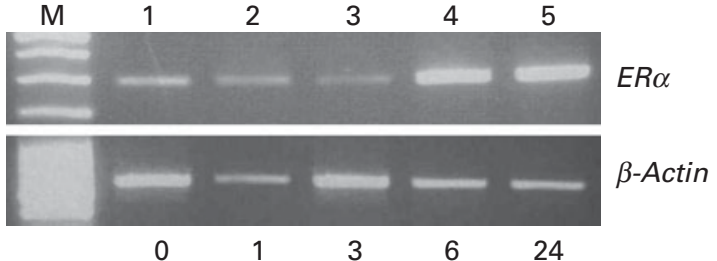

(c)

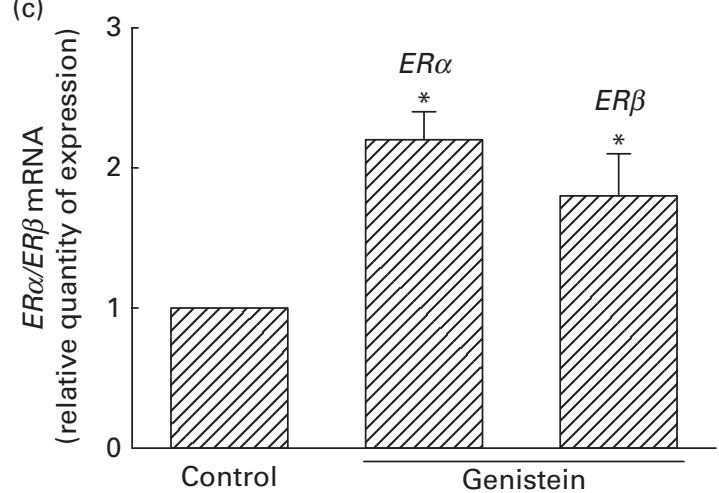

Fig. 3. Effects of genistein on the regulation of the expressions of oestrogen receptor $(E R) \alpha$ and $E R \beta$ mRNA. MC3T3-E1 cells were exposed to (a) 1, 5 and $10 \mu \mathrm{M}$-genistein for $6 \mathrm{~h}$ or to (b) $10 \mu \mathrm{M}$-genistein for $1,3,6$ and $24 \mathrm{~h}$. (a, b) Analysis of ER $\alpha$ mRNA was conducted using a RT-PCR. $\beta$-Actin mRNA was analysed as an internal control. (c) Real-time PCR analyses were conducted to confirm the effects of genistein on the regulation of $E R a$ and $E R \beta$ mRNA expressions. Values are means $(n 4)$, with their standard errors represented by vertical bars. * Mean value was significantly different from that of the control $(P<0.05)$. M, marker of $100 \mathrm{bp}$ DNA ladder.

treatment with $10 \mu \mathrm{m}$-genistein for $24 \mathrm{~h}$ (Fig. 6(b), top panel, lane 2). The amounts of $\beta$-actin mRNA and protein were analysed as internal controls (Fig. 6(a) and (b)). A bioinformatic approach was performed, and the results indicated that 9, 10 and $10 \mathrm{ER} \alpha$-specific DNA-binding elements, respectively, existed in the $5^{\prime}$-promoter regions of the BMP-6, Col I and $O C N$ genes (Fig. 6(c)). After exposure to $10 \mu \mathrm{M}$-genistein for $6 \mathrm{~h}$, the expressions of $B M P-6$, Col $I$ and $O C N$ mRNA were significantly induced (Fig. 6(d), top three panels, lane 2). $\beta$-Actin mRNA was analysed as the internal control.

After exposure to a combined mixture of dexamethasone, ascorbic acid, and $\beta$-glycerophosphate or genistein for $21 \mathrm{~d}$, osteoblast mineralisation was determined (Fig. 7). Treatment of primary rat calvarial osteoblasts with genistein alone did not affect cell mineralisation (Fig. 7(a)). However, when the osteoblasts were exposed to a mixture of dexamethasone, ascorbic acid and $\beta$-glycerophosphate for $21 \mathrm{~d}$, mineralised nodules were obviously increased (Fig. 7(a)). In contrast, co-treatment with the DR and genistein synergistically increased osteoblast mineralisation (Fig. 7(a)). These mineralised nodules were quantified and analysed (Fig. 7(b)). In the control and genistein-treated rat osteoblasts, mineralised nodules were not observed. After exposure to the DR, the nodules were significantly produced. Compared with the DR-treated group, co-treatment with genistein and the DR resulted in a significant twofold increase in osteoblast mineralisation (Fig. 7(b))

\section{Discussion}

Genistein can induce $E R \alpha$ gene expression. The present study showed that after exposure to genistein the levels of ER $\alpha$ in MC3T3-E1 cells were increased in concentration- and timedependent manners. At the same time, ER $\alpha$ mRNA expression was significantly increased by genistein. Thus, genisteininduced $E R \alpha$ gene expression occurred at least by a pretranslational mechanism. The genistein-induced $E R \alpha$ mRNA expression was also confirmed in primary osteoblasts isolated from rat calvaria. In addition, we demonstrated that genistein under the present administered conditions did not cause cytotoxicity in osteoblasts. Liao et al. ${ }^{(28)}$ reported that genistein can stimulate ER $\alpha$ mRNA expression in bone marrow cells. In the present study, we further showed that genistein can induce $E R \alpha$ mRNA and protein expressions in MC3T3-E1 cells and primary rat calvarial osteoblasts. We also demonstrated that $E R \beta$ mRNA expression can be induced by genistein. ER $\alpha$ and ER $\beta$ play vital roles in the mediation of oestrogen-involved regulation of skeletal growth and maintenance ${ }^{(23)}$. However, the levels of human serum oestrogen decrease with ageing $^{(12,14)}$. Genistein, an isoflavone-type phyto-oestrogen, has been reported to have the potential to prevent and treat osteoporosis $^{(18,19)}$. Osteoblasts contribute to bone formation ${ }^{(1,2)}$. Therefore, the present study further showed that genistein can induce $E R \alpha$ gene expression and possibly participate in the regulation of osteoblast activities and bone metabolism.

The translocation of NF- $\mathrm{BB}$ and AP-1 is involved in genistein-induced $E R \alpha$ gene expression. The amounts of nuclear $\mathrm{NF}-\kappa \mathrm{B}$ and c-Jun in the osteoblasts were time dependently

(a)

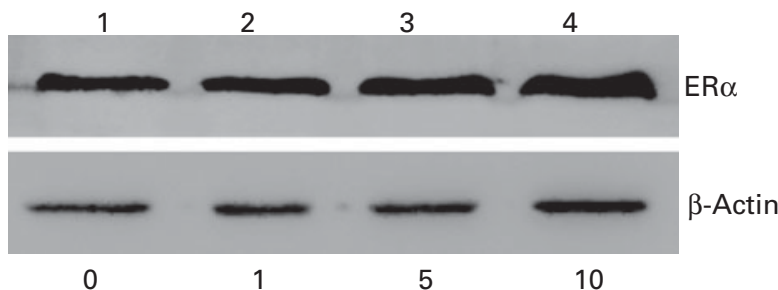

(b)

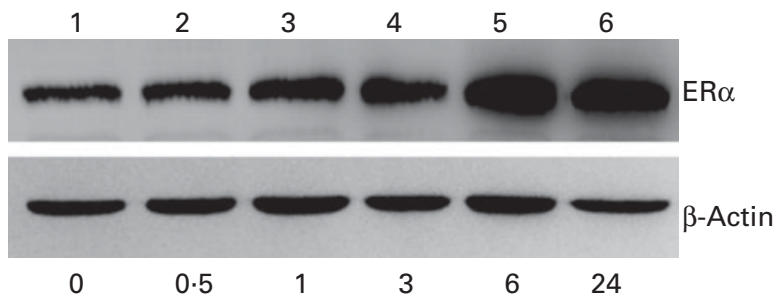

Fig. 4. Effects of genistein on the synthesis of oestrogen receptor (ER) o protein. MC3T3-E1 cells were exposed to (a) 1, 5 and $10 \mu \mathrm{M}$-genistein for $24 \mathrm{~h}$ or to (b) $10 \mu \mathrm{M}$-genistein for $0.5,1,3,6$ and $24 \mathrm{~h}$. (a, b) ER $\alpha$ was immunodetected. The amounts of $\beta$-actin were analysed as internal controls. 
(a)

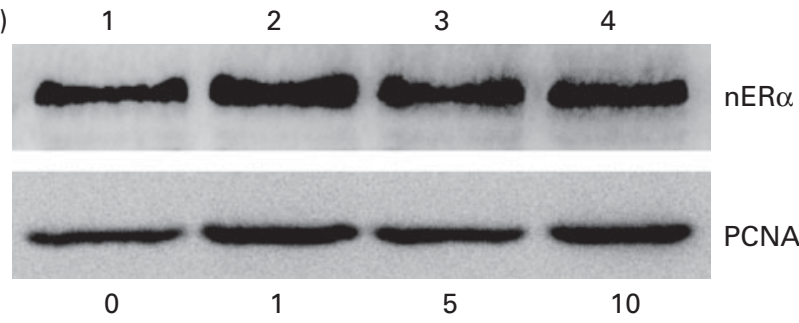

(b)

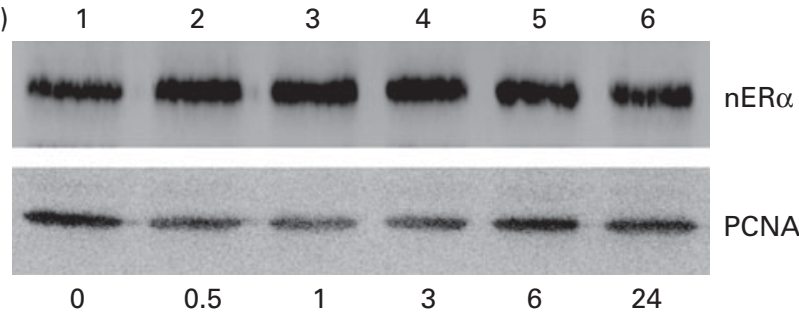

Fig. 5. Effects of genistein on the translocation of oestrogen receptor (ER) a from the cytoplasm to the nucleus (n). MC3T3-E1 cells were exposed to (a) 1,5 and $10 \mu \mathrm{M}$-genistein for $24 \mathrm{~h}$ or to (b) $10 \mu \mathrm{M}$-genistein for $0.5,1,3,6$ and $24 \mathrm{~h}$. The levels of $\mathrm{nER} \alpha$ were immunodetected. The amounts of nuclear proliferating cell nuclear antigen (PCNA) were analysed as internal controls.

up-regulated following genistein administration. c-Jun and c-Fos can bind to each other to form the heterodimeric AP-1, a transcription factor ${ }^{(32)}$. The results of our bioinformatic search revealed that both NF-кB- and AP-1-specific DNA-binding elements exist in the $5^{\prime}$-promoter region of the $E R \alpha$ gene. Thus, genistein-induced $E R \alpha$ gene expression was due to the improved translocation of NF-кB and AP-1 from the cytoplasm to the nucleus. The increased translocation of these two transcription factors simultaneously increases their transactiva-

(a)

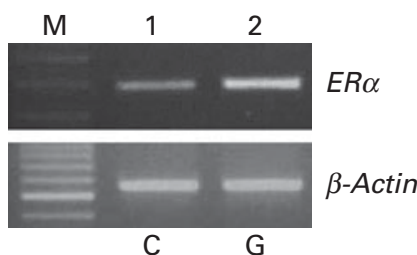

(c)

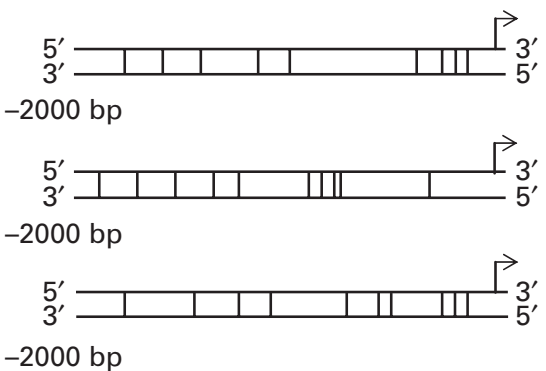

tion activities and induces $E R \alpha$ gene expression. NF-кB and $\mathrm{AP}-1$ are two typical transcription factors that participate in the regulation of osteoblast differentiation and mineralisation $^{(33,34)}$. Targeting NF-кB- and AP-1-transduced signals has been reported to be a promising strategy for treating bone diseases ${ }^{(35)}$. Genistein-induced translocation of NF- $\mathrm{BB}$ and AP-1 can concurrently explain the induction of the expression of the $E R \alpha$ gene and its effects on the promotion of osteoblast activities and bone metabolism.

Genistein can trigger the phosphorylation of MAPK and enhance the translocation of $\mathrm{NF}-\mathrm{\kappa B}$ and AP-1. The present results revealed that exposure of osteoblasts to genistein caused time-dependent increases in the phosphorylation of ERK1/2, JNK1/2 and p38 MAPK. MAPK are serine/threoninespecific protein kinases containing three major enzymes, namely ERK1/2, JNK1/2 and p38 MAPK $^{(36)}$. After phosphorylation, ERK1/2 and p38 MAPK can activate NF-кB and trigger the translocation of this transcription factor into nuclei, which subsequently induces the expressions of certain genes $^{(37)}$. In contrast, the activated JNK1/2 can phosphorylate c-Jun and induce the transactivation activity of $\mathrm{AP}-1^{(38)}$. Accordingly, one of the major reasons explaining the translocation of NF- $\mathrm{KB}$ and AP-1 stimulated by genistein is the phosphorylation of ERK1/2, p38 MAPK and JNK1/2 by this phyto-oestrogen. In oestrogen-involved signalling, the activated ERK1/2 promotes ER $\alpha$-mediated intracellular signal-transducing events ${ }^{(39)}$. In addition, the phosphorylation of MAPK contributes to the regulation of bone remodelling ${ }^{(35)}$. Therefore, genistein-induced phosphorylation of ERK1/2, JNK1/2 and p38 MAPK and subsequent activation of the transcription factors NF- $\mathrm{BB}$ and AP-1 could have multiple functions in the regulation of $E R \alpha$ gene expression and protein activation and improvement of osteoblast maturation.

(b)

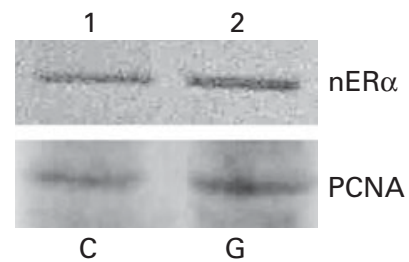

(d)

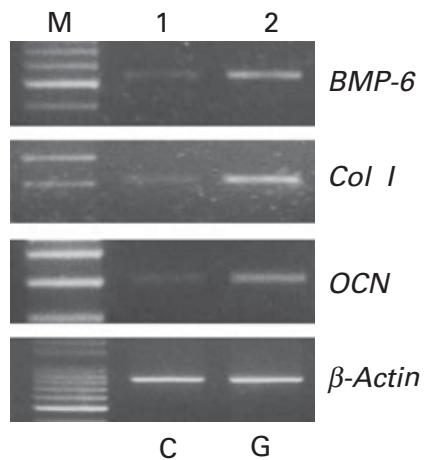

Fig. 6. Effects of genistein on the regulation of the expressions of the oestrogen receptor $(E R) \alpha$, bone morphogenetic protein $(B M P) 6$, collagen type I (Col $I)$ and osteocalcin (OCM) genes in primary rat osteoblasts. Rat osteoblasts prepared from rat calvaria were exposed to $10 \mu \mathrm{M}$-genistein for (a, d) $6 \mathrm{~h}$ and (b) $24 \mathrm{~h}$. (a, d) The levels of $E R \alpha, B M P-6, C o l l$ and OCN mRNA were determined using a RT-PCR. (a, d) $\beta$-Actin mRNA was analysed as an internal control. (b) The amounts of nuclear $\operatorname{ER} \alpha(n E R \alpha)$ were immunodetected. Nuclear proliferating cell nuclear antigen (PCNA) was analysed as an internal control. A bioinformatic approach was used to search the ER $\alpha$-specific DNA-binding elements in the $5^{\prime}$-promoter regions of the BMP-6, Col I and OCN genes. M, marker of 100 bp DNA ladder. 
(a)
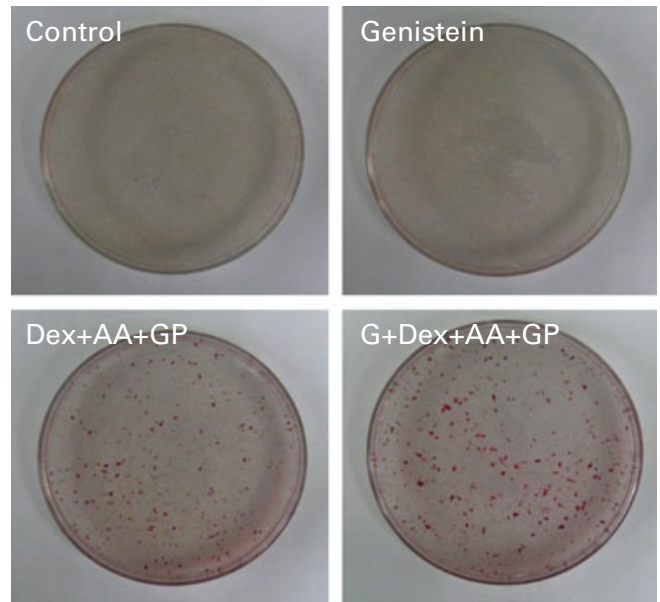

$\mathrm{G}+\mathrm{Dex}+\mathrm{AA}+\mathrm{GP}$

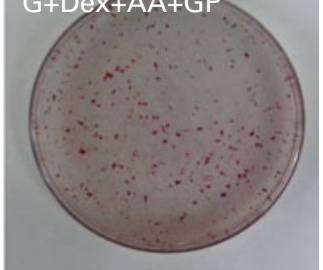

(b)

Fig. 7. Effects of genistein on the mineralisation of primary rat osteoblasts. Rat osteoblasts prepared from rat calvaria were exposed to $10 \mu \mathrm{M}$-genistein (G), a differentiation reagent (DR, including $10 \mathrm{~nm}$-dexamethasone (Dex), $100 \mu \mathrm{g}$ ascorbic acid (AA)/ml and $10 \mathrm{~mm}-\beta$-glycerophosphate (GP)), and a combination of genistein and the DR for $21 \mathrm{~d}$. The drugs were renewed every $2 \mathrm{~d}$. (a) Osteoblast mineralisation was determined using the Alizarin red $\mathrm{S}$ dye-staining protocol. (b) The amounts of mineralised nodules were quantified and analysed.

Genistein stimulates the expressions of the BMP-6, Col I and $O C N$ genes through the activation of $\mathrm{ER} \alpha$ in primary rat osteoblasts. MC3T3-E1 is an osteoblast-like cell line. To confirm the effects of genistein on primary cells, osteoblasts were isolated from neonatal rat calvaria. After exposure to genistein, $E R \alpha$ mRNA and protein expressions were significantly induced. Thus, genistein can also induce $\mathrm{ER} \alpha$ gene expression in primary osteoblasts as that observed in osteoblast-like MC3T3-E1 cells. ER $\alpha$ can act as a transcription factor in the regulation of osteoblast differentiation-related genes, including BMP-6, Col $I$ and $O C N^{(22)}$. The present study showed that in parallel to the increase in the translocation of $\mathrm{ER} \alpha$ into the nuclei, the expressions of $B M P-6, \mathrm{Col} I$ and $O C N$ mRNA in primary rat osteoblasts were simultaneously induced. We also showed that several ER $\alpha$-specific DNAbinding elements are present in the $5^{\prime}$-promoter regions of the $B M P-6, C o l I$ and $O C N$ genes. Therefore, in primary osteoblasts, genistein can induce $E R \alpha$ mRNA expression and protein activation and stimulate the expressions of the $B M P-6, C o l I$ and $O C N$ genes.

Genistein has synergistic effects on the stimulation of mineralisation of primary rat osteoblasts. The present study demonstrated that although genistein alone cannot induce the mineralisation of primary rat osteoblasts, co-treatment with a traditional DR synergistically promotes osteoblast maturation. Osteoblast differentiation and maturation are regulated by a complicated network of various proteins, including BMP, $\mathrm{Col} \mathrm{I}$ and $\mathrm{OCN}^{(5)}$. In osteogenesis, BMP-6 and Col I participate in bone extracellular matrix differentiation and mineralisation $^{(8,9)}$. Col I contributes to osteoblast adhesion and differentiation $^{(11)}$. Increases in the syntheses of these proteins will trigger osteoblast differentiation and mineralisation ${ }^{(5,7,10)}$ In the present study, genistein was shown to induce the expressions of the BMP-6, Col I and OCN genes. Therefore, genistein can promote osteoblast differentiation and bone metabolism by inducing the expressions of these cell differentiation-related genes.

In summary, the present study showed that exposure of MC3T3-E1 cells and primary rat osteoblasts to genistein did not cause cytotoxicity. In contrast, genistein induced $E R \alpha$ mRNA and protein expressions in MC3T3-E1 cells in concentration- and time-dependent manners. As regards the mechanisms, treatment with genistein time dependently increased the phosphorylation of ERK1/2, p38 MAPK and JNK1/2. Sequentially, the levels of nuclear NF-кB and c-Jun were significantly enhanced after genistein administration. In primary neonatal rat calvarial osteoblasts, the effects of genistein on $E R \alpha$ mRNA and protein expressions were also confirmed. Genistein can trigger the translocation of ER $\alpha$ from the cytoplasm to the nucleus. The results of a bioinformatic approach revealed that several $\mathrm{ER} \alpha$-specific DNA-binding elements exist in the $5^{\prime}$-promoter regions of the osteoblast differentiation-related $B M P-6, C o l I$ and $O C N$ genes. In parallel, genistein induced the expressions of $B M P-6, C o l I$ and $O C N$ mRNA in primary rat osteoblasts. Consequently, exposure to genistein synergistically improved the traditional ER-induced osteoblast mineralisation. In summary, the present study showed that genistein can induce $E R \alpha$ gene expression via the activation of $\mathrm{MAPK} / \mathrm{NF}-\kappa \mathrm{B} / \mathrm{AP}-1$ and stimulate osteoblast differentiation and maturation through the ER $\alpha$-dependent induction of the expressions of the BMP-6, Col I and OCN genes. The molecular mechanisms of genistein-involved regulation of the expressions of osteoblast differentiation-related genes, including $B M P-6, \mathrm{Col} I$ and $O C N$, are being studied in our laboratory. The effects of genistein on bone healing using an animal model of bone defects will be our next research focus.

\section{Acknowledgements}

The present study was supported by Wan-Fang Hospital (100wf-eva-10) and the National Science Council (NSC101-2314-B- 
038-003-MY3), Taipei, Taiwan. All authors participated in the design of the present study. M.-H. L. and P.-I. L. carried out the cell culture and drug treatment. M.-H. L., Y.-T. T. and Y.A. C. conducted the assays of cell viability and immunodetection. M.-H. L., Y.-T. T. and Y.-G. C. contributed to the RT-PCR analyses and osteoblast maturation. S.-H. L. and R.-M. C. participated in the data analyses. M.-H. L. and R.-M. C. wrote the initial manuscript draft. R.-M. C. assembled the final version. All authors read and approved the final manuscript. None of the authors has any conflict of interest to declare.

\section{References}

1. Seeman E \& Delmas PD (2006) Bone quality - the material and structural basis of bone strength and fragility. $N$ Engl J Med 354, 2250-2261.

2. Chen RM, Lin YL \& Chou CW (2010) GATA-3 transduces survival signals in osteoblasts through upregulation of $b c l-x_{\mathrm{L}}$ gene expression. J Bone Miner Res 25, 2193-2204.

3. Takeda S \& Karsenty G (2001) Central control of bone formation. J Bone Miner Metab 19, 195-198.

4. Engin F \& Lee B (2010) NOTCHing the bone: insights into multi-functionality. Bone 46, 274-280.

5. Vandenput L \& Ohlsson C (2009) Estrogens as regulators of bone health in men. Nat Rev Endocrinol 5, 437-443.

6. Hung TY, Chen TL, Liao MH, et al. (2010) Drynaria fortunei J. Sm. promotes osteoblast maturation by inducing differentiation-related gene expression and protecting against oxidative stress-induced apoptotic insults. J Ethnopharmacol 131, 70-77.

7. Kugimiya F, Kawaguchi H, Kamekura S, et al. (2005) Involvement of endogenous bone morphogenetic protein (BMP) 2 and BMP6 in bone formation. $J$ Biol Chem 280, 35704-35712.

8. Trzeciakiewicz A, Habauzit V, Mercier S, et al. (2010) Hesperetin stimulates differentiation of primary rat osteoblasts involving the BMP signalling pathway. J Nutr Biochem 21, 424-431.

9. van Leeuwen JP, van Driel M, van den Bemd GJ, et al. (2001) Vitamin D control of osteoblast function and bone extracellular matrix mineralization. Crit Rev Eukaryot Gene Expr 11, 199-226.

10. Mizuno M \& Kuboki Y (2001) Osteoblast-related gene expression of bone marrow cells during the osteoblastic differentiation induced by type I collagen. J Biochem 129, $133-138$.

11. Mathews S, Bhonde R, Gupta PK, et al. (2012) Extracellular matrix protein mediated regulation of the osteoblast differentiation of bone marrow derived human mesenchymal stem cells. Differentiation 84, 185-192.

12. Fiorelli G \& Brandi ML (1999) Skeletal effects of estrogens. J Endocrinol Invest 22, 589-593.

13. Hsu CK, Liao MH, Tai YT, et al. (2011) Nanoparticles prepared from the water extract of Gusuibu (Drynaria fortunei J. Sm.) protects osteoblasts against insults and promotes cell maturation. Int J Nanomedicine 6, 1405-1413.

14. Krum SA (2011) Direct transcriptional targets of sex steroid hormones in bone. J Cell Biochem 112, 401-408.

15. Manolagas SC (2000) Birth and death of bone cells: basic regulatory mechanisms and implications for pathogenesis and treatment of osteoporosis. Endocr Rev 21, 115-137.

16. Eastell R \& Hannon RA (2008) Biomarkers of bone health and osteoporosis risk. Proc Nutr Soc 67, 157-162.
17. Modugno F, Laskey R, Smith AL, et al. (2012) Hormone response in ovarian cancer: time to reconsider as a clinical target? Endocr Relat Cancer 19, 255-279.

18. Usui T (2006) Pharmaceutical prospects of phytoestrogens. Endocr J 53, 7-20.

19. Coward L, Barnes NC, Setchell KDR, et al. (1993) Genistein, daidzein, and their $\beta$-glycoside conjugates: antitumor isoflavones in soybean foods from American and Asian diets. $J$ Agric Food Chem 41, 1961-1967.

20. Poulsen RC \& Kruger MC (2008) Soy phytoestrogen: impact on postmenopausal bone loss and mechanisms of action. Nutr Rev 66, 359-374.

21. Wang TT, Sathyamoorthy N \& Phang JM (1996) Molecular effects of genistein on estrogen receptor mediated pathways. Carcinogenesis 17, 271-275.

22. Dahlman-Wright K, Cavailles V, Fuqua SA, et al. (2006) International Union of Pharmacology. LXIV. Estrogen receptors. Pharmacol Rev 58, 773-781.

23. Sims NA, Clément-Lacroix P, Minet D, et al. (2003) A functional androgen receptor is not sufficient to allow estradiol to protect bone after gonadectomy in estradiol receptordeficient mice. J Clin Invest 111, 1319-1327.

24. Levy N, Zhao X, Tang H, et al. (2007) Multiple transcription factor elements collaborate with estrogen receptor alpha to activate an inducible estrogen response element in the NKG2E gene. Endocrinology 148, 3449-3458.

25. Gruber CJ, Gruber DM, Gruber IM, et al. (2004) Anatomy of the estrogen response element. Trends Endocrinol Metab 15 , 73-78.

26. Pan W, Quarles LD, Song LH, et al. (2005) Genistein stimulates the osteoblastic differentiation via NO/cGMP in bone marrow culture. J Cell Biochem 94, 307-316.

27. Heim M, Frank O, Kampmann G, et al. (2004) The phytoestrogen genistein enhances osteogenesis and represses adipogenic differentiation of human primary bone marrow stromal cells. Endocrinology 145, 848-859.

28. Liao QC, Xiao ZS, Qin YF, et al. (2007) Genistein stimulates osteoblastic differentiation via p38 MAPK-Cbfa1 pathway in bone marrow culture. Acta Pharmacol Sin 28, 1597-1602.

29. Chang HC, Chen TG, Tai YT, et al. (2011) Resveratrol attenuates oxidized LDL-evoked Lox-1 signaling and consequently protects against apoptotic insults to cerebrovascular endothelial cells. J Cereb Blood Flow Metab 31, $842-854$.

30. Wu GJ, Chen TL, Ueng YF, et al. (2008) Ketamine inhibits tumor necrosis factor- $\alpha$ and interleukin- 6 gene expressions in lipopolysaccharide-stimulated macrophages through suppression of toll-like receptor 4-mediated c-Jun N-terminal kinase phosphorylation and activator protein-1 activation. Toxicol Appl Pharmacol 228, 105-113.

31. Lin JW, Chen JT, Hong CY, et al. (2012) Honokiol traverses the blood-brain barrier and induces apoptosis of neuroblastoma cells via an intrinsic Bax-mitochondrion-cytochrome $c$ caspase protease pathway. Neuro Oncol 14, 302-314.

32. Hess J, Angel P \& Schorpp-Kistner M (2004) AP-1 subunits: quarrel and harmony among siblings. J Cell Sci 117, 5965-5973.

33. Kim JM, Lee SU, Kim YS, et al. (2008) Baicalein stimulates osteoblast differentiation via coordinating activation of MAP kinases and transcription factors. J Cell Biochem 104, 1906-1917.

34. Tan TW, Huang YL, Chang JT, et al. (2012) CCN3 increases BMP-4 expression and bone mineralization in osteoblasts. J Cell Physiol 227, 2531-2541.

35. Wu X, Li Z, Yang Z, et al. (2012) Caffeic acid 3,4-dihydroxyphenethyl ester suppresses receptor activator of NF-kappa B 
ligand-induced osteoclastogenesis and prevents ovariectomyinduced bone loss through inhibition of mitogen-activated protein kinase/activator protein 1 and $\mathrm{Ca}^{2+}$-nuclear factor of activated T-cells cytoplasmic 1 signaling pathways. $J$ Bone Miner Res 27, 1298-1308.

36. Manning G, Whyte DB, Martinez R, et al. (2002) The protein kinase complement of the human genome. Science $\mathbf{2 9 8}$, $1912-1934$
37. Karin M (2005) Inflammation-activated protein kinases as targets for drug development. Proc Am Thorac Soc 2, 386-390.

38. Shaulian E (2010) AP-1 - the Jun proteins: oncogenes or tumor suppressors in disguise? Cell Signal 22, 894-899.

39. Driggers PH \& Segars JH (2002) Estrogen action and cytoplasmic signaling pathways. Part II: the role of growth factors and phosphorylation in estrogen signaling. Trends Endocrinol Metab 13, 422-427. 